Research Article

\title{
Examining the Effectiveness of Two Types of Forgiveness Intervention to Enhance Well-Being in Adults from Young to Older Adulthood
}

Olga Zichnali ${ }^{1}$, Despina Moraitou ${ }^{1,}{ }^{*}$, Christos Pezirkianidis ${ }^{2}$, Anastasios Stalikas ${ }^{2}$

1. Lab of Psychology, Section of Cognitive and Experimental Psychology, School of Psychology, Aristotle University of Thessaloniki, Greece; E-Mails: olgazich@psy.auth.gr; demorait@psy.auth.gr

2. Panteion University of Social and Political Sciences, Greece; E-Mails: christospez@hotmail.com; stalikas.anastasios@gmail.com

* Correspondence: Despina Moraitou; E-Mail: demorait@psy.auth.gr

Academic Editor: Lisa Hollis-Sawyer

Special Issue: Got Aging? Examining Later-life Development from a Positive Aging Perspective

OBM Geriatrics

2019 , volume 3 , issue 2

doi:10.21926/obm.geriatr.1902044
Received: October 30, 2018

Accepted: March 23, 2019

Published: April 03, 2019

\begin{abstract}
Background: Interventions that facilitate positive actions and attitudes seem to play an important role in enhancing psychological health. This study examines the effectiveness of two self-guided interventions with the aim to enhance adults' well-being through the cultivation of forgiveness skills.
\end{abstract}

Methods: A total of 11 men and 31 women aged $34-80$ years were involved ( $M=56.57$, S.D. = 13.44). All participants were Orthodox Christians, as the average Greeks are, without belonging to a closed religious community. They were asked to complete questionnaires that measure the sense of well-being, the trait of forgiveness, and avoidance, revenge, and benevolence motivation. Subsequently, they were randomly divided into two groups that corresponded to age, gender, and educational level. One group followed the General ( $\mathrm{n}=$ $22)$, and the other one the Orthodox-Tradition-Enhanced Intervention ( $n=20)$. The two interventions included six steps toward forgiveness. Self-paced sessions were implemented so as the interventions can be completed. On average, the process lasted two weeks.

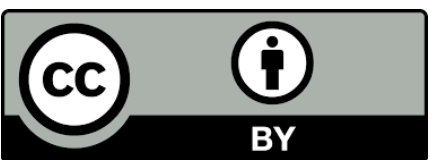

(C) 2019 by the author. This is an open access article distributed under the conditions of the Creative Commons by Attribution License, which permits unrestricted use, distribution, and reproduction in any medium or format, provided the original work is correctly cited. 
Participants were also invited to complete the same questionnaires immediately after the intervention, as well as two weeks after the intervention (follow-up measurement).

Results: The results showed that forgiveness skills and subjective well-being were reinforced through both interventions and increased significantly more in the Orthodox. The primacy of the Orthodox approach has been demonstrated to reduce negative emotions and promote a sense of well-being over time. The possible mechanisms for the effectiveness of the intervention are further discussed.

Conclusions: The findings are promising for the ability of forgiveness interventions, and especially those based on the Orthodox tradition, to improve forgiveness skills and increase mental well-being in adults.

\section{Keywords}

Forgiveness' interventions; orthodox tradition; positive psychology; well-being

\section{Introduction}

In recent years, there has been an increasing interest in forgiveness, as mental health scientists are increasingly recognizing its value in maintaining emotional well-being, physical health, and healthy relationships. It is widely accepted that forgiveness can help reduce negative thoughts and feelings arising from dysfunctional interpersonal relationships [1]. In addition, improving the wellbeing of the wider population, such as reducing mental health problems and increasing positive emotions, is a key policy objective in many countries. To a large extent, the reason behind it is that well-being is associated with a reduction in dangerous health behaviors, such as smoking and excessive alcohol consumption, as well as with increased productivity at work $[2,3]$. It is evident that understanding the factors that promote mental well-being is a vital issue.

Interventions that facilitate positive actions and attitudes can play an important role in enhancing psychological health [2]. Considering previous research, which has shown that unresolved traumatic experiences of the past may contribute to the development of depressive symptoms in later adulthood, it is particularly important to develop interventions that promote forgiveness for adults in advancing age $[4,5]$. Therefore, numerous psychologists have developed structured interventions based on a variety of theoretical models that have effectively reduce the unforgiveness and promote the forgiveness of interpersonal offenses in clinical and non-clinical populations [1].

\subsection{The Effectiveness of Forgiveness Interventions}

Based on experimental studies conducted over the last few years to assess the extent to which forgiveness interventions promote psychological health, forgiveness of others is largely correlated with the improvement of overall mental health. It is widely accepted that those participating in forgiveness interventions report reduced levels of anxiety and depression. In addition, they do better on multiple indicators of physical health and are more willing to forgive others [6]. Forgiveness can also be associated with strong social support since it reduces negative emotions 
such as anger and hostility [7]. Offering and receiving forgiveness have also been proposed to be among the most important psychological and intellectual needs in older adults [8].

According to Weng, Zhang, and Fu, [9] and Li, Shi, and Yang [10], the effectiveness of forgiveness interventions was considered high in well-known mental health benefits such as a lower-level of depressive symptomatology and anxiety. Recent meta-analysis has shown that forgiveness interventions are effective beyond the simple common therapeutic factors involved in the process [11]. Those interventions help the clients avoid facing negative health consequences of unforgiveness [12].

\subsection{The Necessity of Forgiveness Interventions in Older Adults}

Older adults represent a growing proportion of the world's population. Addressing the health needs of the aging population has become an important issue that the global community faces [3]. It is widely known that happiness in the elderly is positively correlated with the health and quality of life [13], strong social and family relationships, great social support and high levels of activity and personal skills [14]. However, older adults represent a group more vulnerable to the loss of happiness and subjective well-being, which can lead to emotional disorders such as depression and anxiety caused by age-related regulatory losses. Therefore, it is worthwhile to help older adults develop strategies and activities that will enable them to maintain their physical and emotional well-being. Interventions to promote mental health, to reduce mental illness and to slow down the decline are essential to the quality of life in this population and to reduce the cost of healthcare. As forgiveness interventions and their empirical study are evolving, it is important to investigate whether these interventions can consistently demonstrate positive effects on the level of forgiveness and mental health in older adults.

Although many forgiveness interventions have been proven to be effective in several groups, it is worth noting that only a few have been applied to the elderly and none of them has clearly addressed the age-related issues.

Hebl and Enright [15] implemented the first psychotherapeutic forgiveness intervention in elderly women. There were 24 female participants with a mean age of 74.5 years who were recruited from a Christian church. One of the including criteria was to have something to forgive and to feel emotionally hurt by a former incident. Participants were randomly assigned to the experimental condition below. In particular, eight weekly group meetings were set up and based on the Enright process model of forgiveness. As an alternative, series of eight weekly meetings were conducted where general topics of interest were discussed and the topic of forgiveness was avoided. Dependent variables included forgiveness scales, self-esteem Inventories, depression Inventory, and State-Trait Anxiety Inventory. Following the 8-week intervention, the forgiveness profiles of the experimental group had higher results at posttest compared to the control group. Both groups showed an important improvement depicted in measures of anxiety and depression.

The intervention of Ingersoll, Campbell, and Ha [4] applied the therapeutic model of Enright's forgiveness in a social group of older adults and extended its approach to two important points. First, they adapted the Enright model to a group intervention for elderly men and women coming from different religious and secular backgrounds. Secondly, they extended the evaluation of the intervention, focusing on the positive results over time. A total of 20 men and women, aged 57-82, took part in two different groups of forgiveness, each of whom met weekly for 8 sessions with a 4- 
month follow-up period. Forgiveness measures, as well as the biopsychosocial function, were collected before and after the group's intervention. The results revealed that the participants showed long-term improvement in forgiveness and depression, short-term improvement in physical health, and change in relation to anxiety or social support.

Allemand, Steiner, and Hill [16] have developed a forgiveness intervention that includes common data with other previous interventions but focuses on the needs of older adults. They recruited 81 older adults from the German-speaking part of Switzerland through a university database and agencies for older adults. The participation criteria were the experience of a serious and unresolved interpersonal harm and interest in acquiring skills to deal with this harm. The average age of participants was 70.1 years. The sample included mostly women (75.6\%). With their consent, the participants were randomly assigned either to a direct treatment $(n=52)$ or to a waiting control condition $(n=26)$ with a greater number of participants in the treatment condition. The intervention consisted of two sessions of 3.5 hours of psycho-educational groups with a week's delay between the two sessions and included a treatment manual. The results showed the effectiveness of the intervention for the values of many variables, including avoidance motivation, painful sense of offense, cognitive reappraisals and negative effects. While the effect in the posttest was not so satisfactory, the effect in the follow-up was impressive. Evidently, this means that changes in the process of forgiveness are rather slow and long-lasting. Interestingly, no signs of impact on the motives of kindness and positive affect were found. In other words, the intervention was primarily successful since it reduced negative situations.

To summarize, these findings indicate the promise of forgiveness interventions for older adults not only to understand and cope with the past, present and future self-confinement but also to reduce the negative emotional responses or the symptoms of depression [16].

\subsection{Basic Models of Forgiveness Interventions}

The existing literature supports two different levels or types of experience of forgiveness. The "Cognitive Model" focuses on making forgiveness decisions and experiencing forgiveness without eliminating feelings of injustice. This experience proves to be only marginally effective in reducing stress levels and/or improving emotional health. "Emotional forgiveness" showed an emphasis on replacing negative with positive emotions towards the offender. Furthermore, it overcomes resentment, indignation, anger, bitter feelings, and offers the opportunity to heal the wound. All of these are positive psychophysiological changes and have more direct consequences for health and well-being [17].

The existing research distinguishes two basic models of forgiveness interventions: "processbased interventions" and "decision-based interventions". On the one hand, process-based models include the use of a set of cognitive, emotional and behavioral strategies for a longer period. On the other hand, decision-based approaches have a more concise duration and seem to rely more on cognitive components [18].

Although similar in content, process-based models belong to one of two types of experience of forgiveness, which are also the most commonly investigated. The first one was developed by Enright and the Human Development Study Group [19] and the second one by Worthington [20]. Both start out with making the decision to forgive and end with emotional forgiveness. 
The first model developed by Enright includes four phases: the stage of anger awareness, the phase of forgiveness, the stage of work to develop empathy for the perpetrator, and the stage of deepening to find meaning in pain $[11,18]$.

The second model, REACH, was developed by Worthington and focuses on the forgiveness process [21]. At the beginning of the process, participants are invited to assess their current situation and feelings about an unforgiven transgression. The forgiveness is initially defined, its benefits are described, and beliefs about forgiveness are investigated. Before the next step, the participants are invited to decide whether to offer forgiveness or reconsider their decision later. Then, they work to gain emotional forgiveness through the REACH process in five steps. R-E-A-C-H is an acronym indicating a course of forgiveness in five steps.

In the first step, participants recall $(R)$ the specific hurt and emotions associated with the target transgression. Because the development of empathy is conceptualized as a central facilitative process in forgiving [22], participants work to develop empathy (E) for the offender by understanding the other's perspective and factors that may have contributed to the offenses without criticizing or justifying their behavior. In the next step, participants are invited to give an altruistic $(A)$ response to forgive the offender based on the experiences of the participant that have been forgiven, thus, reinforcing humility. At a subsequent time, participants commit (C) to maintain the forgiveness they experienced and extend it [23]. In the latter phase, participants develop cognitive-behavioral, emotional, or environmental control strategies to hold $(\mathrm{H})$ or maintain forgiveness when they recall their hurt or anger [21, 24]. Upon completion of the REACH process, forgiveness is extended by applying the model to up to ten other events that have not been fully forgiven, and with the commitment to maintain a more forgiving attitude in their lives $[1,21]$.

\subsection{Variety of Individual and Self-Managed Interventions}

Properly targeted, evidence-based, self-directed interventions for psychological problems are important alternatives to individual care in the form of psychotherapy [25]. Self-help interventions are the main treatments where the problems are causing moderate distress and access to qualified physicians is limited [26]. Sometimes, they are suggested as a complement to psychotherapy [23].

There are many ways of managing self-help interventions. Two recent studies evaluated the effectiveness of REACH forgiveness in a self-directed form [27, 28]. A workbook was offered electronically to students who chose to complete the questionnaires and workbooks within 2 weeks. Greer and his colleagues felt that the use of a workbook was just as effective as the forms of the psychologically guided group in which the students participated [28].

In a further investigation of two workbook forgiveness, Harper and his colleagues [28] and Greer and his colleagues [27] studied students who worked in a 6/7-hour workbook to forgive a person of their choice. Students, after receiving credit for their participation, were assigned to the waiting group or the direct intervention group which was completed within 2 weeks. A reminder from a relevant class teacher was given at the end of the first week and another one at the end of the second week before the date on which the program was completed.

While these interventions have been successful in increasing forgiveness, the conditions for a study conducted at a university with credit, as compared to a completely voluntary community 
intervention, are different. Therefore, it was considered important to study the implementation of a voluntary, interactive, internet-based approach in a community adult sample [23].

\subsection{Online Self-Managed Interventions}

Internet users and service providers appreciate the internet-based interventions on mental health for their low cost, 24-hour availability, anonymity, and ease of remote access [29]. However, all internet-based interventions are not identical [30]. Depending on the attention required by the site manager, they might be differentiated; they can range from minimum attention (i.e. simply making the site available to an open source) with periodic checks and personal encouragement for follow-up to full on consults with mental health providers upon request. To maximize participation, these interventions are often short (sometimes only a few hours), offer audio and video elements, and include personalized interactions and the use of automated attendance reminders.

Meta-analysis found that internet-based psychotherapeutic interventions are effective $[29,30]$. However, they usually have relatively high rates of abandonment, with half of the participants in the community sample leaving [30-33]. Consequently, the calculation of the factors that predict persistence is crucial. Nation, Wertheim, and Worthington [23] completed the first study that examined the effectiveness of an online, self-managed intervention based on the REACH forgiveness model. Since many participants left before the program was completed, the predictors of persistence in the program were also examined.

Participants ( $\mathrm{N}=130$ adults, 122 women, average age 48 years) completed the pre-intervention evaluation and were randomly assigned either to the Immediate Treatment group (IT) or to the Delayed Treatment (DT) group. Of these, 23 participants in the IT group and 13 in DT group completed the 7-hour REACH forgiveness modules and post-intervention evaluation. In total, 32 participants completed the 3-month follow-up [23].

The results showed that the Immediate Treatment group reported improvements in overall and emotional forgiveness and reductions in avoidance motivations after the intervention. Nevertheless, motivations of revenge, decisive forgiveness, and well-being indicators have not changed. Most post-intervention improvements were maintained in the 3-month follow-up. In this online intervention, persistence was predicted by perspective taking, willingness to forgive the offender, and conscientiousness. Follow-up after three months has maintained positive effects, particularly on overall well-being and emotional forgiveness, as well as on the characteristics of forgiveness [23].

\subsection{The Effectiveness of Forgiveness Interventions within the Context of Religion}

Although several evidence-based interventions have been developed to promote forgiveness, only a few religiously oriented interventions, which promote forgiveness, have been investigated among the multitude of interventions for adults. Since our study focuses on comparing forgiveness interventions within a secular and religious context, we studied other religion-based interventions. Most of them are adjustments to Worthington's emotional forgiveness through the REACH Forgiveness program. The REACH model was adapted to Christian clients and tested in controlled trials by various researchers [34-36].

Rye and Pargament [37] studied women who tried forgiving their former partner in an unsuccessful relationship. Rye, Pargament, Pan, Yingling, Shogren, and Ito [38] studied women 
who wanted to forgive a divorced partner. In both cases, the intervention was based on the REACH model. Lampton and his colleagues [34] (along with Christian college students), Stratton and his colleagues [35] (with Christian college students), and Worthington and his colleagues [36] (with Filipino church members) used religiously adapted versions of REACH.

Worthington, Hook, Davis, and McDaniel meta-analyzed 51 samples from 46 studies that examined the outcomes of religion-accommodative therapies and non-religious spiritual therapies. They found out that religious treatments had clear positive gains from pre-test to post-test, and the gains were maintained at follow-up. However, when the studies involving a control group were analyzed, religious treatments were more effective than those applied to a control group for the improvement of psychological symptoms. Compared to an active alternative treatment on psychological symptoms, religious treatments were not necessarily more effective than controls. In fact, they were better at provoking changes in spiritual measures (however, those spiritual changes were not maintained at follow-up). At the most restrictive level of comparison between a secular treatment and a religious treatment, both were similar and effective except for religious or spiritual adaptation, secular and religious treatments. Treatments that are hosted with religious ambitions exceeded the dismantling-design alternative treatments in spiritual $(d=.33)$ but not in psychological outcomes [39].

Recent reviews [40] and meta-analysis [41] of religious and spiritually accommodated psychotherapeutic treatments showed that strictly accommodated religious or spiritual treatments, when compared to the comparable secular treatment, produce similar positive results in changing mental health symptoms and provide spiritual benefits beyond the secular treatments for religious clientele.

Reflecting on the research about Christian clients, Worthington, Li, and Ho distinguished twelve principles for accommodating Worthington's secular intervention for Christian clients. The principles are (1) to provide a religious context by beginning with meditations about forgiveness taken from Christian Scriptures and writings of Christian writers; (2) use examples of forgiveness taken from Christian Scriptures or Christian writers; (3) ascribe permanent change to God and justify the use of the psychological approach by referring to the REACH steps as forms that shape the working of God in the life of people, whereas the real work of forgiveness is produced by the working of God; (4) describe Scriptural mandates in the Christian faith to forgive (Matthew 6:12, 14-15); (5) invite people to make a decision to forgive by offering the grudge to God as a sacrifice early in the treatment and returning later in the group to offer the unforgiveness to God with more heartfelt intention; (6) refer to the support one might receive by other members of one's faith; (7) justify replacing unforgiving emotions with empathy, sympathy, compassion, and love because those virtues are valued in the Christian faith; (8) invite people to identify heroes of forgiveness, drawing on their faith and Christian community to identify examples; (9) invite people to pray for the people who harmed or offended them; (10) imply that people should copy Jesus; (11) suggest that people forgive because they have been forgiven by God and also because they have been forgiven by others; (12) draw on the idea that one can have a Christian mission by promoting forgiveness in the world through being a model and also explicitly teaching forgiveness to others [42].

These principles were used to design our own forgiveness intervention oriented to the Christian Orthodox faith. We considered the use of these principles as necessary since Christians often think 
of theological reasons to describe experiences of forgiveness [43] and tend to engage in spiritual processes such as prayer when they forgive an offender [44].

\subsection{Forgiveness from the Perspective of Orthodox Christian Tradition and Life}

Despite the relative infancy of forgiveness as a discipline in the psychological community, the study of forgiveness has profound roots in Christianity, where forgiveness and reconciliation seem to be more than a complete process. From a Christian theological point of view, the reason why God forgives humanity is for the explicit purpose of reconciliation. Therefore, this makes it difficult to envision an emotional form of forgiveness that can be separated from the goal of reconciliation.

The Christian theologian L. Gregory Jones [45] criticized the model of forgiveness proposed by Western therapies that have been accepted by American culture. Jones argued that the influences of therapeutic conceptions have encouraged a privatized forgiveness, in which forgiveness ceases to be an interpersonal discipline and has become an intrapersonal exercise. Jones used the term privatized forgiveness to describe the act of making one party's heart and mind feel better. He described this as a cheapened form of forgiveness that ignores the relational context. Privatized forgiveness is an easy answer to the difficult task that Christian forgiveness requires.

From a theological perspective, true forgiveness culminates in the healing of what has been broken. It is a struggle where both culpability and wrongdoing are examined and eventually overcome by community's rehabilitation. The purpose of forgiveness is not to feel better, but to deepen and enrich the community. It is a way of life; not an inner way of life, but a way of living with others. This perspective approaches that of Orthodox theology [45].

Forgiveness is a central issue in Christian faith, but Christian traditions sometimes vary in how they understand and approach the process of forgiveness. As this study investigated the effectiveness of an intervention enriched with elements from the Christian Orthodox tradition, it was considered important to refer to the specific meaning and conditions of forgiveness within it. From the way the concept of forgiveness is attributed to English and Greek, there is a potential differentiation in its interpretation. The meaning in English is attributed to the word: for-give-ness, which includes a transaction. According to Enright and the Human Development Study Group [19], forgiveness is a gift offered by the victim to the perpetrator, although he does not deserve it and is distinguished from approval, justification, reconciliation, and forgetting, as there may be forgiveness without reconciliation. A constant controversial aspect of the definition is whether it involves the development of positive feelings and thoughts towards the perpetrator, or whether it could simply be the absence of negative thoughts and emotions [46].

The concept in Greek is attributed to the words "syn + horo", that is to coexist or be together in the same place or to bridge a difference. The interpretation of the concept in Greek involves the concept of coexistence, which is more closely related to the approach of Orthodoxy. In Orthodox theology, forgiveness is projected to be a prominent feature of the nature of God, which, while not fitting throughout the universe, being infinite and incomprehensible, fell within the narrow limits of the human nature of his creature in order to heal and unite it with the Divine nature. Forgiveness is inextricably linked to the unlimited compassion of God, that is, the unconditional love for his creature and his omnipotence. An indication of the omnipotence of God is not primarily thought to be the Creation of the world or the obstruction of evil, but his love, which leads to forgiving the person who is insulting him. On the Cross of Christ, forgiveness was shed to 
make love come true. The crucified love of Christ and forgiveness are the foundation of Christian life. It is the foundation upon which faith is based but at the same time the climax for every spiritual effort. What is required of people is to preserve and make their permanent possession the gift of forgiveness. And this depends solely on their reconciliation with their fellowman [47].

In the context of Orthodox faith, the need for forgiveness is not only a psychological need. Consequently, all members of the church are the limbs of the body of Christ and all together comprise the church community. Forgiveness is considered as the virtue that makes people alike with God and unite with God and other people. Moreover, since Orthodox theology refers to the need for forgiveness, it focuses not only on the gain of psychological calmness and selfimprovement but also on the development of sympathy that is love for the perpetrator. As such, it emphasizes not only on the releasement of negative thoughts but also on the development of sympathy, even on the love for the perpetrator [48].

The lack of love and the cultivation of revenge lead to the deterioration and death of both mental and physical well-being. St. John Chrysostom regards forgiveness as the source of all goods, while grudging and denial of reconciliation as a source of mental suffering. Such is the nature of evil, he writes characteristically, destroying the one who gives birth to it (MG 49, 101).

Saint John the Sinai calls the resentment poison of the soul, canker of the mind, alienation of love, nail crammed into the soul and persistent grudge [49]. Unforgiving, aversion and revenge nudge the man from the divine Grace and pollute the atmosphere in which they live and act. On the contrary, the presence of God's love is beneficial to humans and their relationships. In this perspective, the so-called "enemies" are ultimately victims of evil, ignorance (Acts 3:17) and human weakness. Therefore, the most effective treatment of evil is to overcome it when the victim manages to escape the logic of return and not identify with them. In Orthodox theology and life, the elimination of evil is made possible by forgiveness, forbearance, and love that overwhelm the self-preservation instinct and defeat evil at its root: the denial or frustration of love and the depreciation of the human person [50].

Jesus, in the Sermon on the Mount, referring to perfection, begins from non-resistance to injustice, and then proceeds to the highest degree of forgiveness, to the extreme degree of love, to the love of the enemies. This supreme expression of love, without faith, without honest and practical repentance, without the power of the Cross and the grace of the Holy Spirit, is impossible to be incarnated. Love to the enemies in the teaching of Christ becomes very specific and therefore directly therapeutic. God treats all people as beloved children.

In the culmination of Christian life, in the Divine Liturgy, and even shortly before receiving the body and blood of Christ, Christians make two public confessions that are the prerequisites of Holy Communion; the confession of truth with the "Symbol of Faith" and the confession of love with "Sunday prayer". As everyone confesses and at the same time expects the future brotherly unity to experience in the Kingdom of God as His children, there is no resentment in their hearts. In the name of this section, Christians struggle to forgive. The vision of this gift and the share in Christ's life is the strongest reinforcement in the truly difficult task of forgiving the enemy.

As forgiveness is a particularly central subject in the Orthodox Christian tradition and since the Greeks have been brought up in this tradition, we assumed that an orthodox religious intervention will be more effective than a secular forgiveness intervention. We believe that this might be the case for several reasons. First, all Christians seem to value forgiveness and so it would be possible to "read into" the religious aspect of forgiveness to which they will probably respond positively. 
Secondly, it was likely that Christians would find religious programs offering participants consistency with their worldview and increased opportunities for religious/spiritual coping. Thirdly, it was likely that Christians exposed to religious intervention could find greater reliance on spiritual support networks. Furthermore, as it has been seen from previous investigations, a Christian intervention for Christian clients was emphasized as it was more effective than a secular intervention [51, 52].

\subsection{The Present Study}

Although forgiveness is strongly supported by the Orthodox Tradition, there is a gap in research into the contribution of forgiveness programs to adults' mental health in the context of the Greek reality. The latter explains why it was considered necessary to design and implement the two following programs. The first one was used in the intervention called "General" and the second one, which was enriched with elements from Christian Orthodox Tradition, was used in the intervention named "Orthodox". They were developed and adapted to the Greek culture based on the REACH forgiveness model because it has been proven effective in a wide range of populations [53]. It has been adapted and tested in Christian societies [34-38] as well, and it has been investigated in pairs or in individual counseling [20,54-56].

The current study investigated the effectiveness of two interventions, General and Orthodox, on increasing the forgiving skills and well-being in a sample of adults living in urban areas in Greece, using a self-managed interactive method in electronic and paper form.

The main research hypothesis was that participants in both interventions would report increased levels of forgiveness and mental well-being after the interventions [Hypothesis 1a]. Participants in the Orthodox intervention would report a significantly higher improvement compared to the participants of the General intervention [Hypothesis $1 \mathrm{~b}$ ]. In addition, it was assumed that the positive result would be maintained for at least 2 weeks after the interventions [Hypothesis 1c].

The purpose of this study is to examine whether the forgiveness intervention in the Christian Orthodox context is more effective than the comparable secular intervention. To date, no research has been published that examines the efficacy of forgiveness interventions in these two parallel fields simultaneously.

\section{Materials and Methods}

\subsection{Design and Participants}

Initially, 78 adults aged 22 to 80 years from the community responded to invite for an online forgiveness study and completed preliminary measures. Among them, 34 was excluded; 7 of which did not meet exclusion criteria, 8 declined to participate and 19 did not have enough time to complete the participation. Participant flow is described in Figure 1, the CONSORT flow chart (see Figure 1). 


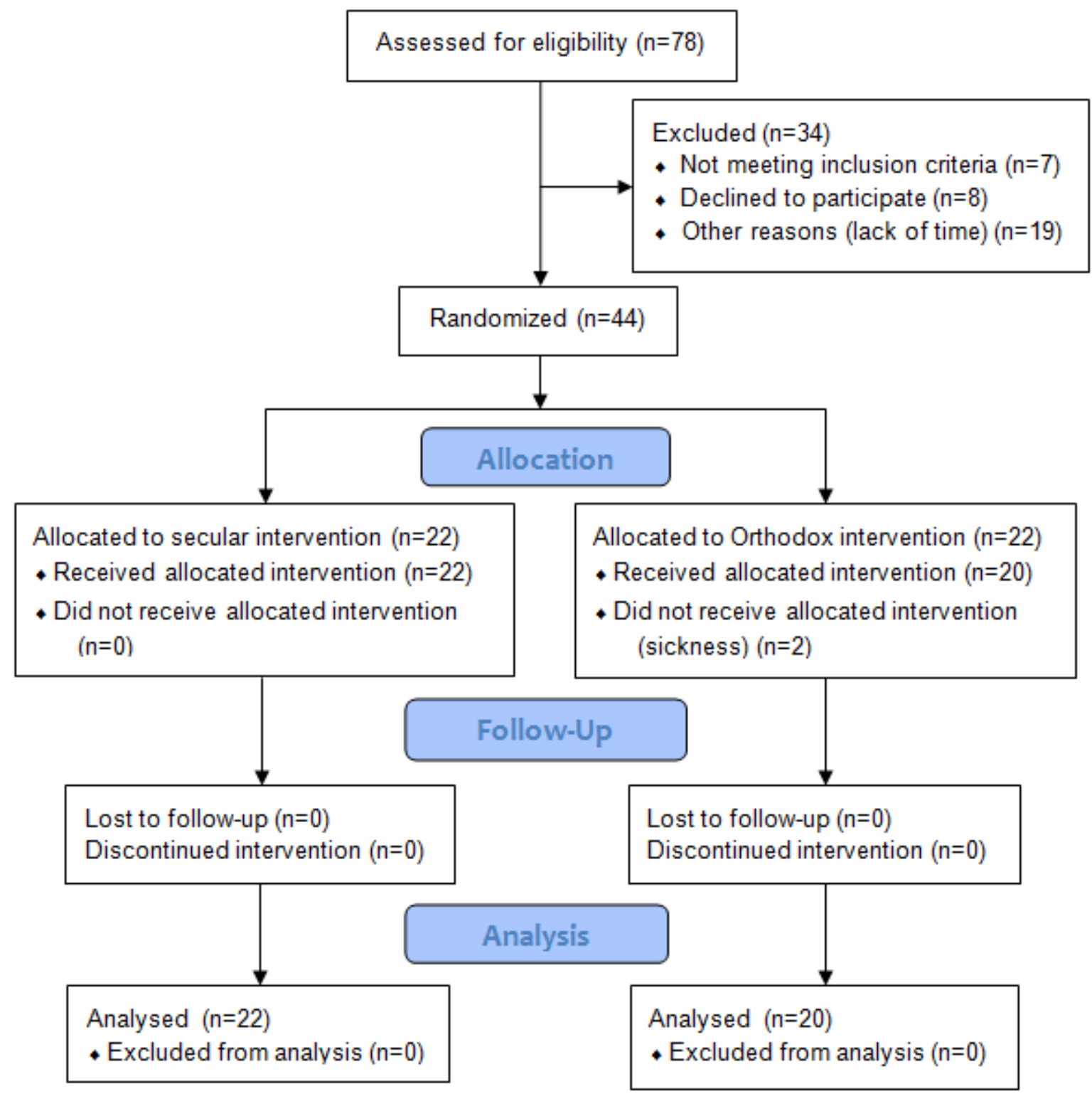

Figure 1 Consort flow chart.

Eventually, a total of 11 men (26.2 \%) and 31 women (73.8 \%) who had experienced unresolved interpersonal harm, with an average age of 56.57 years (S.D. $=13.45$ ) were randomly assigned to one of two interventions. Of these, 24 (13 in the General and 11 in the Orthodox) had full-time employment and 18 were retired ( 9 in the General and 9 in the Orthodox). Regarding the educational level, 17 (77.3 \%) had a university degree. The two groups were homogeneous in the severity of the offense and in the degree of religiosity. All participants were Orthodox Christians and were not members of a closed religious group. They also did not differ significantly in age, $\chi^{2}(1)$ $=.11, p>.05$ (General: $34-79$ years old, $M=55.91$. Orthodox: $34-80$ years old, $M=57.30$ ). educational level, $\chi^{2}(1)=1.46, p>.05$, gender, $\chi^{2}(1)=.28, p>.05$, and employment status, $\chi^{2}(1)$ $=.07, p>.05$ (see Table 1 ).

The sample was convenience, matched the typical population of Greek society and collected through visits to educational institutions, employment centers for older adults, and the wider community. It included 42 adults between 34-80 years old living in three Greek cities. They all had 
been wronged and wrongdoing included abandonment, infidelity, psychological abuse, date rape, marital emotional abuse, and an undesirable relationship. Participation was optional without any reward.

Table 1 Demographic characteristics of participants in the General and Orthodox Intervention.

\begin{tabular}{|c|c|c|c|c|c|c|}
\hline \multirow[t]{2}{*}{ Variables } & \multicolumn{2}{|c|}{ General } & \multicolumn{2}{|c|}{ Orthodox } & \multirow[t]{2}{*}{$x^{2}(1)$} & \multirow[t]{2}{*}{$\bar{p}$} \\
\hline & $\mathrm{M}$ & S.D. & M & S.D. & & \\
\hline Age (in years) & 55.91 & 13.43 & 57.30 & 13.43 & .11 & $>.05$ \\
\hline Men \% (n) & \multicolumn{2}{|c|}{$27.3 \%(6)$} & \multicolumn{2}{|c|}{$25 \%(5)$} & .28 & $>.05$ \\
\hline Women \% (n) & \multicolumn{2}{|c|}{$72.7 \%(16)$} & \multicolumn{2}{|c|}{$75 \%(15)$} & & \\
\hline Education PGT \% (n) & \multicolumn{2}{|c|}{$77.3 \%(17)$} & \multicolumn{2}{|c|}{$60 \%(12)$} & 1.46 & $>.05$ \\
\hline Full-employment \% (n) & \multicolumn{2}{|c|}{$59.1 \%(13)$} & \multicolumn{2}{|c|}{$55 \%(11)$} & .07 & $>.05$ \\
\hline
\end{tabular}

\subsection{Measures}

\subsubsection{Demographic Features Sheet}

Initially, participants completed demographic information related to gender, age, educational level, and employment status. Moreover, using a 5-point "Likert" scale, they have characterized their life, in general, from very pleasant to very unpleasant.

\subsubsection{The PERMA-Profiler}

The PERMA-Profiler [57] defines five major pillars that together contribute to a person's sense of well-being; specifically, the term "PERMA" represents the pillars of positive emotions, engagement, relationships, meaning, and accomplishment (measured by three items each). Additionally, an overall well-being score can be computed as the mean of the five subscales total scores and a single item tapping Overall Happiness. Moreover, seven items measuring health, negative emotions, and loneliness are also included in the questionnaire giving complementary information about other well-being indices. However, this information was not given in the present study. Hence, the measure consists of 23 items in total scored on an 11-point Likert-type scale anchored by " $0=$ never" to " $10=$ always" or " $0=$ not at all" to " $10=$ completely".

The factorial structure of the PERMA-Profiler scale has been confirmed in a Greek sample [58] and was found to consist of five factors, corresponding to the original structure. Cronbach's alphas for each factor, as calculated for the original instrument and the Greek version, respectively, were as follows: for Positive affect: $\alpha=.88$ and $\alpha=.85$, for Engagement: $\alpha=.72$ and $\alpha=.57$, Relationships: $\alpha=.82$ and $\alpha=.75$, Meaning: $\alpha=.90$ and $\alpha=.78$, and Accomplishment: $\alpha=.79$ and $\alpha=.73$. Also, both in the original study and the validation study in Greece, the measure demonstrated acceptable cross-time stability, and evidence for convergent and divergent validity. However, the findings of both studies suggest that researchers should interpret the results concerning the Engagement subscale with caution since it demonstrates marginal to unacceptable 
Cronbach's alpha and Spearman-Brown values of internal consistency, ranging from .53 to .81 for the construction sample and between .40 and .73 for the Greek sample.

\subsubsection{Heartland Forgiveness Scale (HFS)}

The ability to forgive as a predisposition was measured by the Heartland Forgiveness Scale [59]. For this scale, consisting of 18 items, the translation, and adaptation into Greek by Moraitou was used [60]. According to its creators, it includes three factors - subscales: the first, examines the ability to forgive one's self with items such as, "Over time, I understand myself for the mistakes I have made". Cronbach's $\alpha$ reliability for this subscale is .75 . The second subscale refers to the ability to forgive others and includes items such as, "If some people are bad at me, I always think badly about them (reversal)". Cronbach's $\alpha$ for this subscale is .78. The third subscale examines the ability to forgive by accepting situations that cannot be controlled with items such as, "It is indeed difficult for me to accept negative situations for which no one is blamed". It has Cronbach's $\alpha=$.79. Regarding the Greek version used in the study, the answers are given on a Likert type scale from 1 = almost always wrong for me, to $4=$ almost always true for me.

At this point, it is worth mentioning that the aforementioned structure has not been confirmed in Greece. A study of the role of gratitude and forgiveness in adapting to retirement in the Greek community-dwelling older adults [61] has revealed two instead of three expected theoretical factors in the Heartland Forgiveness Scale (HFS). The number of factors was determined on the basis of the Kaiser criterion, which led to five factors and the Cattell criterion which limited them to only two factors. Items with loads equal to or greater than 0.30 have been taken into further account. The first factor was labeled "Time as Assistant in Cognitive Acceptance of Negative Situations (eigenvalue $=3.65$ )", while the second was labeled "Emotional Forgiveness (eigenvalue $=2.29$ )". The reliability of the two factors was $\alpha=.75$ for the first one, and $\alpha=.63$ (low reliability) for Emotional Forgiveness. A similar structure of the scale was also found in a previous study involving Greek older adults [60].

\subsubsection{Transgression-Related Interpersonal Motivations Inventory (TRIM)}

The Transgression-Related Interpersonal Motivations Inventory (TRIM) was constructed by McCullough [22,62] and his colleagues and was used by Person and Worthington [24] in a selfmanaged workbook to promote forgiveness. According to its creators, when people forgive they tend to experience (a) reduced motivations of avoidance, (b) reduced motivations for revenge, and $(c)$ increased forbearance or goodwill for the offenders. The questionnaire includes two subscales. The first subscale (TRIM A) refers to the motivations of avoidance and revenge and consists of items such as, "I'd keep as much distance between us as possible" or " I'll make him or her pay". The second subscale (TRIM B) refers to the motivation of forbearance and consists of items like, "I looked for the source of the problem and tried to correct it" or "I have given up my hurt and resentment". Participants are invited to choose an unforgivable insult and evaluate their current thoughts and feelings, indicating their degree of agreement or disagreement with a total of 24 items. Cronbach's reliability rating for avoidance and revenge motivations given by the authors who developed the scale is: $\alpha \geq .85$. For forbearance motivations it is: $\alpha>$.85. [62].

In order to test the structural validity of the subscale for the Avoidance and Revenge Motivations (TRIM A), an exploratory factor analysis was applied to the relevant data, which 
revealed a major factor (Kaiser \& Cattell criteria) in which all questions were loaded with values greater than or equal to .35. The value of the Kaiser-Meyer-Oklin index (KMO) was .83 and Bartlett's test of sphericity was statistically significant, $\chi^{2}(66)=292.08, p<.001$. The factor had an eigenvalue equal to 6.00 and explained $50.00 \%$ of the total variance. Cronbach's $\alpha$ for this subscale was .90 (see Table 2).

Table 2 The factorial structure of two subscales of the Transgression Related Interpersonal Motivations Inventory (TRIM).

\begin{tabular}{|c|c|c|}
\hline & \multicolumn{2}{|c|}{$\begin{array}{l}\text { Motivations of avoidance and } \\
\text { revenge (factor loadings) }\end{array}$} \\
\hline 1. I'll make him or her pay. & \multicolumn{2}{|r|}{.78} \\
\hline 2. I'd keep as much distance between us as possible. & \multicolumn{2}{|r|}{.76} \\
\hline 3. I wish that something bad would happen to him/her. & \multicolumn{2}{|r|}{.82} \\
\hline 4. I'd live as if he/she doesn't exist, isn't around. & \multicolumn{2}{|r|}{.72} \\
\hline 5. I wouldn't trust him/her. & \multicolumn{2}{|r|}{.61} \\
\hline 6. I want him/her to get what he/she deserves. & \multicolumn{2}{|r|}{.67} \\
\hline 7. I'd find it difficult to act warmly toward him/her. & \multicolumn{2}{|r|}{.44} \\
\hline 8. I'd avoid him/her. & \multicolumn{2}{|r|}{.71} \\
\hline 9. I'm going to get even. & \multicolumn{2}{|r|}{.80} \\
\hline 10. I'd cut off the relationship with him/her. & \multicolumn{2}{|r|}{.57} \\
\hline 11. I want to see him/her hurt and miserable. & \multicolumn{2}{|r|}{.83} \\
\hline 12. I'd withdraw from him/her. & \multicolumn{2}{|r|}{.67} \\
\hline \multicolumn{3}{|r|}{$\begin{array}{l}\text { Motivations of forbearance } \\
\text { (factor loadings) }\end{array}$} \\
\hline 1. I looked for the source of the problem and tried to cor & ect it. & .77 \\
\hline \multicolumn{2}{|l|}{ him/her, expressed love, showed concern, etc. } & .85 \\
\hline 3. I made an effort to be more friendly and concerned. & & .81 \\
\hline 4. I did my best to put aside the mistrust. & & .59 \\
\hline 5. I tried to make amends. & & .82 \\
\hline 6. I was willing to forget the past and concentrate on the & present. & .81 \\
\hline $\begin{array}{l}\text { 7. Even though his/her actions hurt me, I still have goodv } \\
\text { him/her. }\end{array}$ & ill for & .79 \\
\hline $\begin{array}{l}\text { 8. I want us to bury the hatchet and move forward with } c \\
\text { relationship. }\end{array}$ & & .81 \\
\hline $\begin{array}{l}\text { 9. Despite what he/she did, I want us to have a positive } \\
\text { relationship again. }\end{array}$ & & .79 \\
\hline 10. I have given up my hurt and resentment. & & .35 \\
\hline 11. forgive him/her for what he/she did to me. & & .80 \\
\hline $\begin{array}{l}\text { 12. I have released my anger so I could work on restoring } \\
\text { relationship to health. }\end{array}$ & our & .69 \\
\hline
\end{tabular}


Similarly, to test the structural validity of the subscale for forbearance motivations (TRIM B), exploratory factor analysis was applied to the relevant data, which revealed a major factor (Kaiser \& Cattell criteria) in which all questions were loaded with a load higher or equal to .35. The value of the Kaiser-Meyer-Oklin (KMO) index was .89 and Bartlett's test of sphericity was statistically significant, $\chi^{2}(66)=316.80, p<.001$. The factor had an eigenvalue of 6.79 and explained $56.57 \%$ of the total variance. Cronbach's $\alpha$ was found to be .93 (see Table 2).

\subsection{Intervention and Procedure}

The measures were administered online using Google forms. Participants who completed the measures at the pretest were randomly assigned to either the General or the Orthodox intervention and received the address of the website with the corresponding program aimed at improving mental and physical health through the cultivation of forgiveness. The two programs were specifically designed for research purposes, and their difference was that one used components from Orthodox Faith and Tradition that support the value and necessity of forgiveness while the other program did not. For those who have had difficulty accessing the web, the printed version of the questionnaire or program was provided. At the beginning of the process, participants had to choose a nickname to maintain their anonymity. Then, they were instructed to devote at least one hour for each section and reflect on it for one or more days. After the introductory clarification of the way and time of the process, participants were asked to remember a moderate offense that was not forgiven and to report the thoughts and feelings associated with it. The six practical sections for the cultivation of intellectual and forgiving skills were presented and instruction was given to the participants to answer the questions for thought after reading the texts, and to think about them in their spare time. Participants also had to send researchers their nickname whenever they participated in completing a section to verify the correct participation in the process. Six sections followed with the steps for forgiveness.

In the first section, the forgiveness of the literary texts or texts from the Orthodox Faith and Life (for the Orthodox edition) has been approached in order to reveal its value and necessity. Then, participants were asked to take a position and decide on forgiveness by making a written statement of their intentions.

In the second section, clarifications were given about the definition of forgiveness as a decision and as an emotional experience to avoid any misunderstandings that would create difficulties in the process. In the Orthodox intervention, the conceptual approach to the concept of forgiveness was differentiated and combined with the general attitude towards adversity.

In the third section, participants were encouraged to recall the harmful event from the point of view of an objective observer in a positive way. In the Orthodox intervention, ways to remove the pain and release from the accumulated anger in the context of Christian forbearing and love were suggested.

The fourth section focused on cultivating empathy for the perpetrator of the offense as its conquest is considered a central process to support forgiveness. This was done through an attempt to understand the perpetrator's perspective and the factors likely to have contributed to the offending conduct without neglecting the misconduct. In order to understand the vulnerability of human nature and to develop compassion and sympathy for the perpetrator, participants were invited to recall their personal reactions and feelings in cases where they themselves hurt 
someone else. In the Orthodox intervention, an emphasis was placed on personal empowerment through the experience of the love of God and the human view in the light of the divine image.

In the fifth section, the participants were asked to recall cases that they themselves made a mistake, writing a letter of gratitude to the one who offered them forgiveness to strengthen their humbleness. They were then encouraged to overcome the obstacles and offer themselves an altruistic answer to forgiveness by writing a hypothetical letter to the one who hurt them. Finally, they pledged to keep forgiveness and expand it. In the Orthodox intervention, special mention was given to overcoming the obstacles, achieving total forgiveness and cultivating feelings of love and compassion for all indiscretions.

In the latter section, strategies were developed to maintain forgiveness and emotional peace in crucial periods that revive pain or anger. In the Orthodox intervention, special emphasis was placed on seeking meaning in pain and injustice through the mystery of the Cross.

After the completion of the six Program Sections, which lasted two weeks, the participants were asked to resubmit the same questionnaires. During the process, participants were able to communicate electronically or live with the other participants, while maintaining their full anonymity. In addition, a pilot testing concerning the way of participating in the program in its electronic or printed form or in live communication showed that all versions lead to similar results. Almost all of those who completed the participation combined the personal study with at least one personal communication (see Table 3).

Table 3 The six sections, with the steps to forgive in the General (secular) and Orthodox Christian (religion) intervention.

\begin{tabular}{ll}
\hline General Intervention & Orthodox Christian Intervention \\
\hline $\mathbf{1}^{\text {st }}$ Forgiveness in literary & Forgiveness in texts of the Orthodox Christian faith and \\
texts & tradition. \\
"The resentment is like & "Our Father forgive us our trespasses, as we forgive those who \\
taking poison and waiting for & trespass against us". \\
the other person to die". & Examples of the saints' life
\end{tabular}
McCourt

$\mathbf{2}^{\text {nd }}$ Defining forgiveness as a decision and as an emotional experience

Defining forgiveness and combining with the general attitude of the Orthodox Christian Tradition towards adversity. "Defending individual rights and claiming individual well-being ultimately contributes to the restoration of misery. Walking on the path of forgiveness means the opening of the heart and the choice of comprehension and compassion for what life presents".

$3^{\text {rd }}$ Recalling the harmful event in a positive way An exercise in three stages:

1. Recall injustice.

2. Changing the perspective

3. Removal of pain using the arms
Recalling the harmful event by suggesting ways for the removal of pain in the context of Christian love.

An exercise in three stages:

1. Recall injustice with a brief but warm heart praying

2. Changing the perspective

3. Removal of pain raising hands to prayer 
$4^{\text {th }}$ Cultivating empathy for the perpetrator of the offense.

Role Playing

"We are all able to make a mistake"

\section{$5^{\text {th }}$ Altruism and}

Commitment: Offering the gift of forgiveness.

A letter of gratitude.

Obstacles to full emotional forgiveness.

A hypothetical letter expressing forgiveness

\section{$6^{\text {th }}$ Keeping Forgiveness:}

Strategies to Maintain

Emotional Peace

Review of the steps taken in the previous SECTIONS.

Get experience in controlling your thoughts.
Cultivating empathy for the perpetrator of the offense with emphasis on personal empowerment through the experience of the love of God and the human view in the light of the divine image.

Role Playing

A different view of another's error through the view of a saint "Resisting pain through forgiveness, heals and releases from the negative effects of destructive anger.

We can't forgive if we do not strengthen ourselves".

Altruism and Commitment: Offering the gift of forgiveness with a special emphasis on ways to cultivate feelings of love and compassion for all.

A letter of gratitude because you have been forgiven. Three internal steps to complete forgiveness. A hypothetical letter expressing forgiveness. "I will not give you my hatred". Antoine Leiris "The Greek mother" Earhart Kestner

Keeping Forgiveness: Strategies to Maintain Emotional Peace, with special emphasis on seeking the meaning in pain and injustice through the mystery of the Cross.

Seeking meaning of life and freedom.

Christian love for their friends and enemies.

"You can't always control what is happening in your life, but you can always control what you will feel and what you will do about what's happening to you".

The authors asserted that all procedures contributing to this work complied with the ethical standards of the relevant national and institutional committees for human experimentation and with the Helsinki Declaration of 1975, as revised in 2008. All participants participated voluntarily in the study. They were informed about the procedure and the aim of the study, and subsequently, they provided their written consent for participation.

\section{Results}

The SPSSv.25.0 statistical data analysis software package (IBM Corp., 2017) was used for data processing.

Mixed-measures ANOVAs (2X3) were applied to the variables of the study in order to examine the main effect of the type of intervention, the main effect of time of measurement, as well as the potential interaction effects. Repeated measures ANOVAs were subsequently applied to examine the time of measurement effects in each intervention group separately. Finally, MANOVA was used to examine the type of intervention effects at each level of time of measurement. 


\subsection{The Effects of Intervention Type and Assessment Time on HFS}

Heartland Forgiveness Scale (HFS) data were analyzed using mixed-measures ANOVA 2 (Between Subjects factor $=$ intervention: levels 2: General / Orthodox) $\times 3$ (Within Subjects factor $=$ assessment time: levels 3: pretest / posttest / follow up). There was a significant main effect of the type of intervention, $F(1,40)=5.64, p=.02, \eta_{p}{ }^{2}=.12$, and assessment time, $F(2,82)=82.13, p$ $<.001, \eta_{p}{ }^{2}=.67$. There was also an important interaction effect, $F(2,80)=22.37, p<.001, \eta_{p}{ }^{2}=.36$. In regards to the main effect of the within subjects factor (time), the Bonferroni post-hoc test showed that the posttest HFS score was significantly higher than the pretest score, $1-\mathrm{J}=16.55, p$ $<.001$, and the follow-up score was also significantly higher than the pretest score, $1-\mathrm{J}=14.52, p$ $<.001$. The application of MANOVA, $F(3,38)=13.22, p<.001, \eta_{p}{ }^{2}=.51$ and a series of one-way ANOVA showed that there was a significant effect of intervention on the level of forgiveness in the posttest, $F(1,40)=6.31, p<.05, \eta_{p}{ }^{2}=.14$, and in the follow-up measurement, $F(1,40)=6.31, p$ $<.01, \eta_{p}{ }^{2}=.27$. The Orthodox Intervention group scored significantly higher in the posttest and higher in the follow-up, compared to the General Intervention group (see Figure 2).

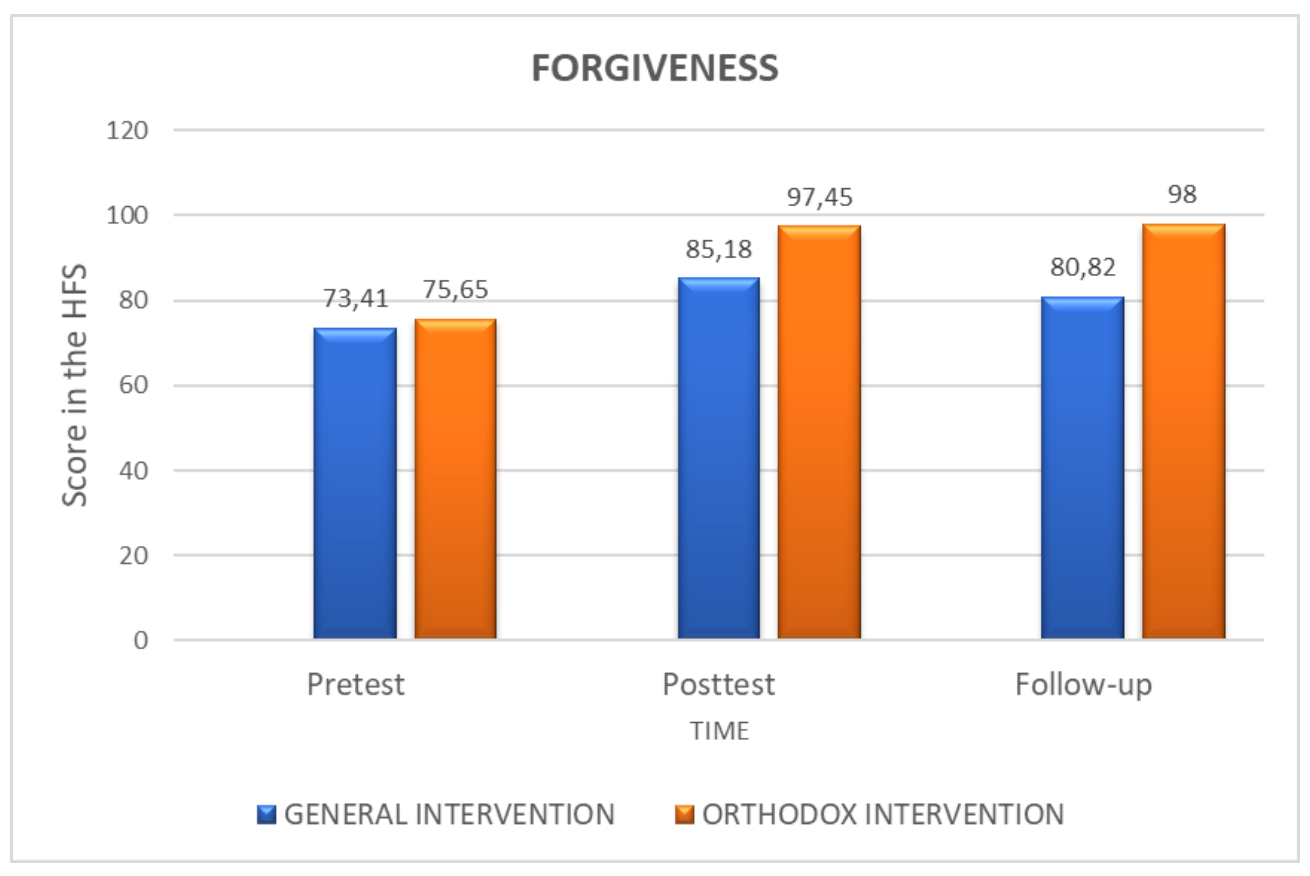

Figure $\mathbf{2}$ The score of the two groups of intervention in the Heartland Forgiveness Scale (Means).

To further examine in more detail the role of the assessment time in forgiveness, repeated measures ANOVAs were conducted for the General group and the Orthodox group independently. General group: $F(2,42)=30.70, p<.001, \eta_{p}{ }^{2}=.59$, Orthodox group: $F(1.45,27.46)=111.58, p<.001$, $\eta_{p}{ }^{2}=.85$. The results showed that the General Intervention group scored significantly higher in the posttest than the pretest, $\mathrm{I}-\mathrm{J}=11.77, p<.001$, significantly higher in the follow-up than the pretest, $\mathrm{I}-\mathrm{J}=7.41, p<.001$, but scored significantly lower than the posttest in the follow-up, I-J $=-4.36, p$ $=.04$.

In the Orthodox Intervention group, repeated measures ANOVA showed that the score of measurement in the posttest was significantly higher than pretest, I-J $=21.80, p<.001$, the score in the follow-up was also significantly higher than pretest, I-J $=22.35, p<.001$, and did not differ 
significantly from the posttest score, Ipretest-J $=.55, p=1.00$. That is, the positive effect of the intervention was maintained.

\subsection{The Effects of Intervention Type and Assessment Time on Perma-Profiler}

The application of 2 (group) $\times 3$ (time of assessment) mixed-measures ANOVA on the data of the Well-being indicator as measured by the PERMA-Profiler showed a significant interaction effect of time and intervention, $F(1.73,69.22)=31.40, p<.001, \eta_{p}{ }^{2}=.44$. Also, there was a significant main effect of time of measurement, $F(1.42,58.19)=41.51, p<.001, \eta_{p}{ }^{2}=.50$. The Bonferroni post-hoc test showed that the posttest PERMA score was significantly higher than the pretest score, $\mathrm{I}-\mathrm{J}=10.98, p<.001$, and the follow-up score was also significantly higher than the pretest score, $\mathrm{I}-\mathrm{J}=9.95, p<.001$. The application of MANOVA, $F(3,38)=18.97, p<.001, \eta_{\mathrm{p}}{ }^{2}=.60$, and a series of one-way ANOVA showed that there was a significant effect of intervention on wellbeing indicator only in the follow-up measurement, $F(1,40)=7.51, p<.05, \eta_{p}^{2}=.16$. The Orthodox Intervention group scored significantly higher in the follow-up measurement compared to the General Intervention group.

To further examine the role of the assessment time in well-being, repeated measures ANOVAs were conducted for the General group and the Orthodox group independently. General group: $F(2$, $42)=7.14, p<.05, \eta_{p}{ }^{2}=.25$, Orthodox group: $F(1.44,27.38)=111.55, p<.001, \eta_{p}{ }^{2}=.85$. In the General Intervention group, posttest score was significantly higher than the pretest score, $I-\mathrm{J}=$ $5.59, p<.05$. However, the follow-up score was not significantly higher than the pretest score, $I-J=$ 2.59, $p=.27$. That is, the effect of the intervention was not maintained.

In the Orthodox Intervention group, the repeated measures ANOVA showed that posttest score was significantly higher than pretest, $\mathrm{I}-\mathrm{J}=16.90, p<.001$, the follow-up score was also significantly higher than the pretest score, $\mathrm{I}-\mathrm{J}=18.05, p<.001$, but it did not differ significantly from the posttest score, $\mathrm{I}-\mathrm{J}=1.55, p=.63$. That is, the Orthodox intervention group in the follow-up maintained the effect of the intervention (see Figure 3 ).

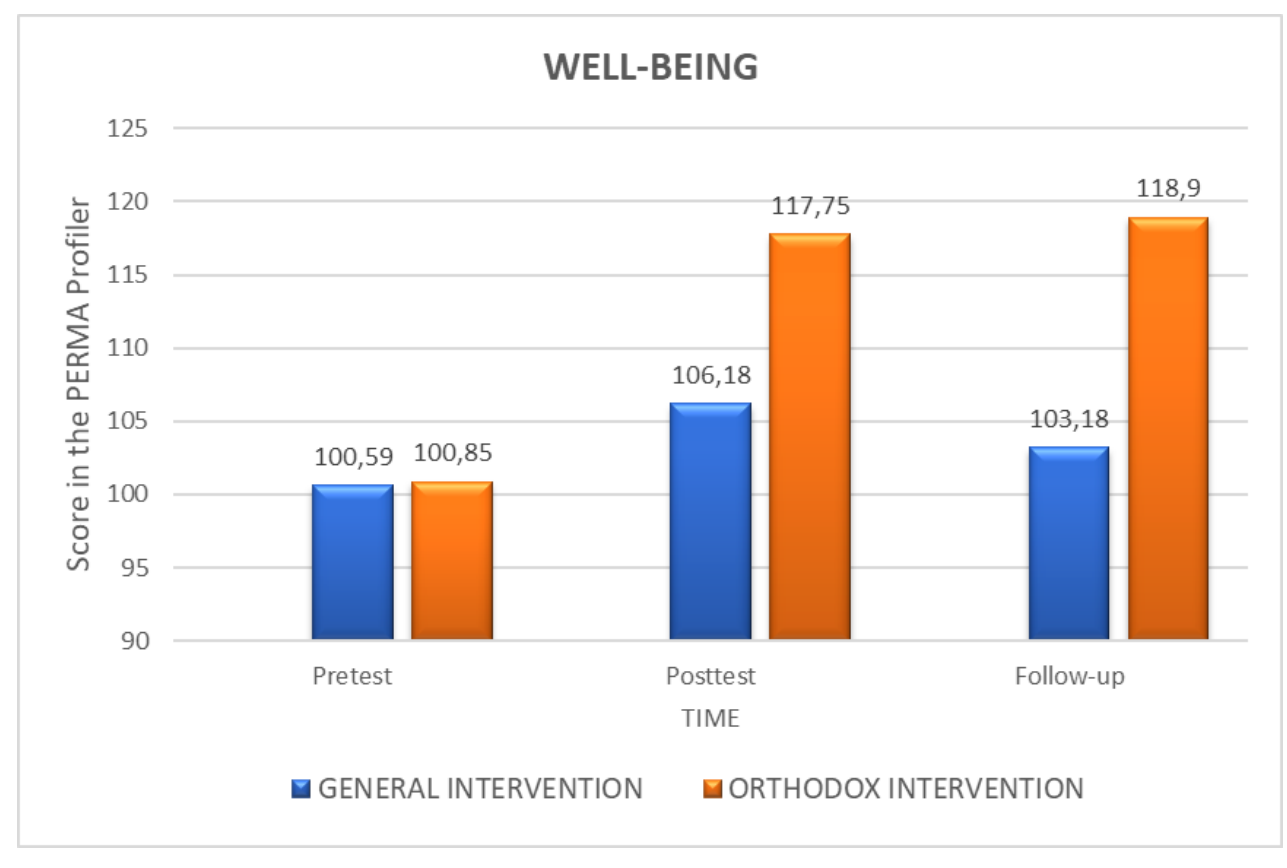

Figure 3 The score of the two groups of intervention in the Perma-Profiler scale (Means). 


\subsection{The Effects of Intervention Type and Assessment Time on TRIM A}

The mixed-measures ANOVA 2 (intervention type) $\times 3$ (assessment time) in the data of the Avoidance and Revenge Motivations inventory (TRIM A) showed a statistically significant main effect of the type of intervention, $F(1,40)=6.46, p=.015, \eta_{p}{ }^{2}=.14$, and of the time of measurement, $F(1.49,61.11)=65.50, p<.001, \eta_{p}{ }^{2}=.62$. Also, there was a statistically significant interaction effect, $F(1.597,63.89)=7.95, p<.05, \eta_{p}{ }^{2}=.17$. Regarding the main effect of the within subjects factor (time), the Bonferroni post-hoc test showed that posttest score of the Avoidance and Revenge Motivations was significantly lower than the pretest, $\mathrm{I}-\mathrm{J}=-8.12, p<.001$, and the follow-up score was also significantly lower than the pretest score, $1-\mathrm{J}=-7.86, p<.001$. The application of MANOVA, $F(3,38)=5.57, p<.05, \eta_{p}{ }^{2}=.31$, and a series of one-way ANOVA showed that there was a significant effect of intervention type on the level of avoidance and revenge motivations as measured by the TRIM A, in the posttest, $F(1,40)=9.25, p<.05, \eta_{p}^{2}=.19$, and in the follow-up, $F(1,40)=11.16, p<.01, \eta_{p}{ }^{2}=.22$. The Orthodox Intervention group scored significantly lower on motivations of avoidance and revenge in the posttest and in the follow-up measurement, compared to the General Intervention group (see Figure 4).

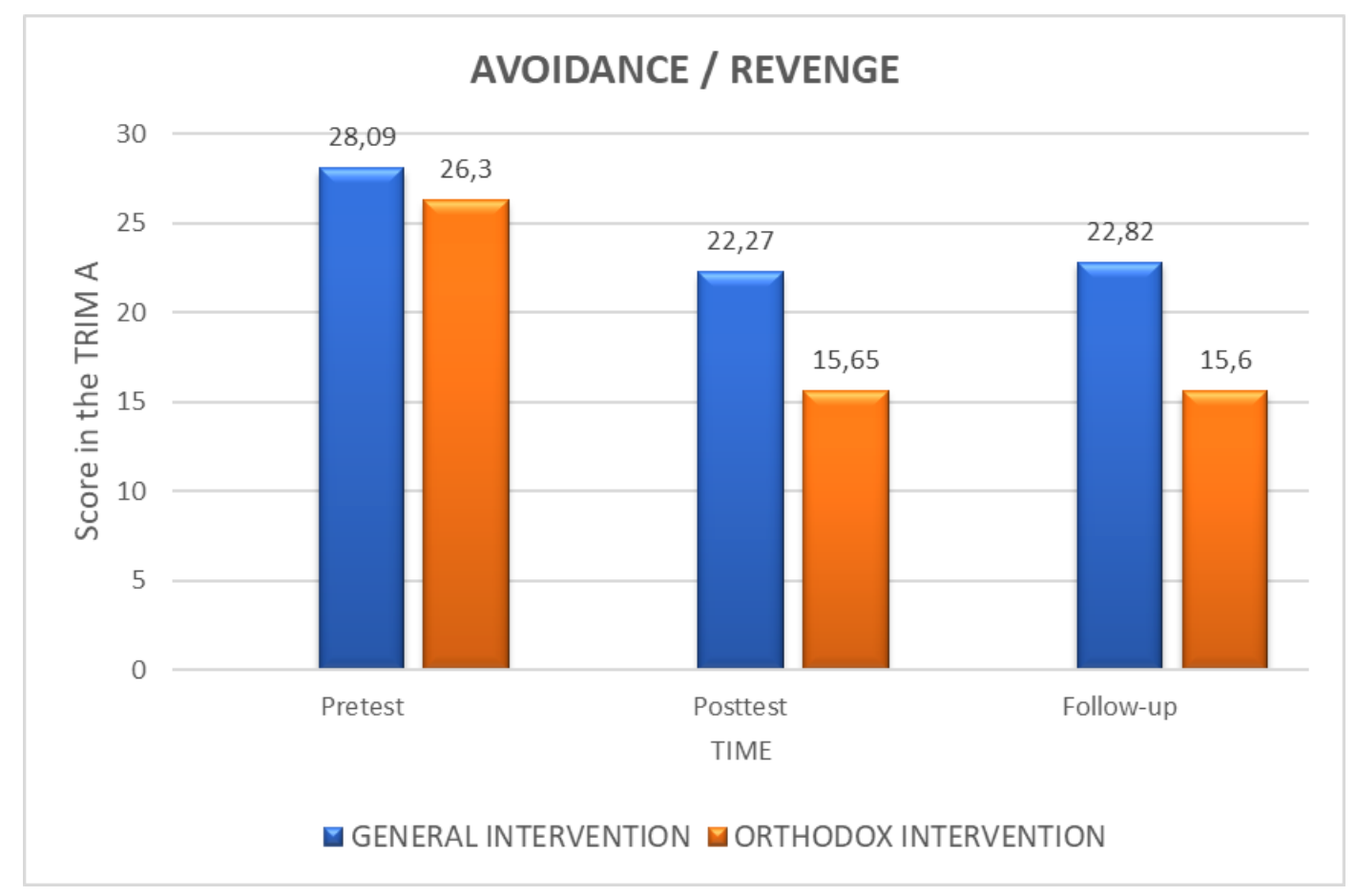

Figure 4 The score of the two groups of intervention in the Avoidance and Revenge Motivation Inventory (Means).

To further examine in more detail the role of the assessment time in motivations of Avoidance and Revenge, repeated measures ANOVA were conducted for the General group and the Orthodox group independently. General group: $F(1.49,31.24)=31.62, p<.001, \eta_{p}{ }^{2}=.60$, Orthodox group: $F(1.65,31.41)=45.69, p<.001, \eta_{p}^{2}=.71$. The results showed that in the General Intervention group the posttest score was significantly lower than the pretest score, $\mathrm{I}-\mathrm{J}=-5.82, p$ $<.001$, the follow-up score was also significantly lower than the pretest score, $1-J=-5.27, p<.001$, 
and it did not differ from the posttest score, $\mathrm{I}-\mathrm{J}=-.05, p=1.00$. That is, the positive effect of the intervention was maintained.

In the Orthodox Intervention group, repeated measures ANOVA showed that posttest score was significantly lower than pretest, $\mathrm{I}-\mathrm{J}=-10.65, p<.001$, follow-up score was also significantly lower than the pretest score, $\mathrm{I}-\mathrm{J}=-10.70, p<.001$, and did not differ significantly from posttest score, $\mathrm{I}-\mathrm{J}=1.00$. That is, the positive effect of the intervention was maintained.

\subsection{The Effects of Intervention Type and Assessment Time on TRIM B}

Finally, mixed-measures ANOVA 2 (intervention type) $\times 3$ (assessment time) applied to the data of the inventory of benevolence motivations (TRIM B) showed a statistically significant main effect of the type of intervention, $F(1,40)=8.96, p=.005, \eta_{p}{ }^{2}=.18$, and the time of measurement, $F$ $(1.59,62.24)=46.71, p<.001, \eta_{p}^{2}=.53$. There was also a statistically significant interaction effect, $F(1.63,65.16)=9.04, p=.001, \eta_{p}{ }^{2}=.18$. Regarding the main effect of the within subjects factor (time), the Bonferroni post-hoc test showed that the posttest score (TRIM B) was significantly higher than the pretest, $\mathrm{I}-\mathrm{J}=8.86, p<.001$, and the follow-up score was also significantly higher than the pretest score, $\mathrm{I}-\mathrm{J}=8.41, p<.001$. The application of MANOVA, $F(3,38)=6.09, p<.05, \eta_{\mathrm{p}}{ }^{2}$ $=.33$, and a series of one-way ANOVA showed that there was a significant effect of intervention type on the level of benevolence motivations as measured by the inventory (TRIM $B$ ) in the posttest measurement, $F(1,40)=10.26, p<.05, \eta_{p}{ }^{2}=.20$, and in the follow-up, $F(1,40)=14.86, p$ $<.001, \eta_{p}{ }^{2}=.27$. The Orthodox Intervention group scored significantly higher in posttest and in the follow-up, compared to the General Intervention group.

To further examine the role of the assessment time in benevolence motivations, repeated measures ANOVAs were conducted for the General group and the Orthodox group independently. General group: $F(2,42)=18.09, p<.001, \eta_{p}{ }^{2}=.46$, Orthodox group: $F(1.63,30.96)=38.38, p<.001$, $\eta_{p}{ }^{2}=.67$. The results showed that in the General Intervention group, the posttest benevolence motivations score was significantly higher than pretest, $I-J=6.00, p<.001$, the follow-up score was also significantly higher than the pretest score, $\mathrm{I}-\mathrm{J}=4.77, p<.05$, and did not differ significantly from the posttest score, $\mathrm{I}-\mathrm{J}=-1.23, p=.69$. That is, the positive effect of the intervention was maintained.

In the Orthodox Intervention group, repeated measures ANOVA showed that the posttest score was significantly higher than the pretest score, $\mathrm{I}-\mathrm{J}=12.00, p<.001$, the score in the follow-up was also significantly higher than the pretest score, $\mathrm{I}-\mathrm{J}=12.40, p<.001$, and did not differ significantly from posttest score, $\mathrm{I}-\mathrm{J}=.40, p=1.00$. That is, the positive effect of the intervention was maintained (see Figure 5). 


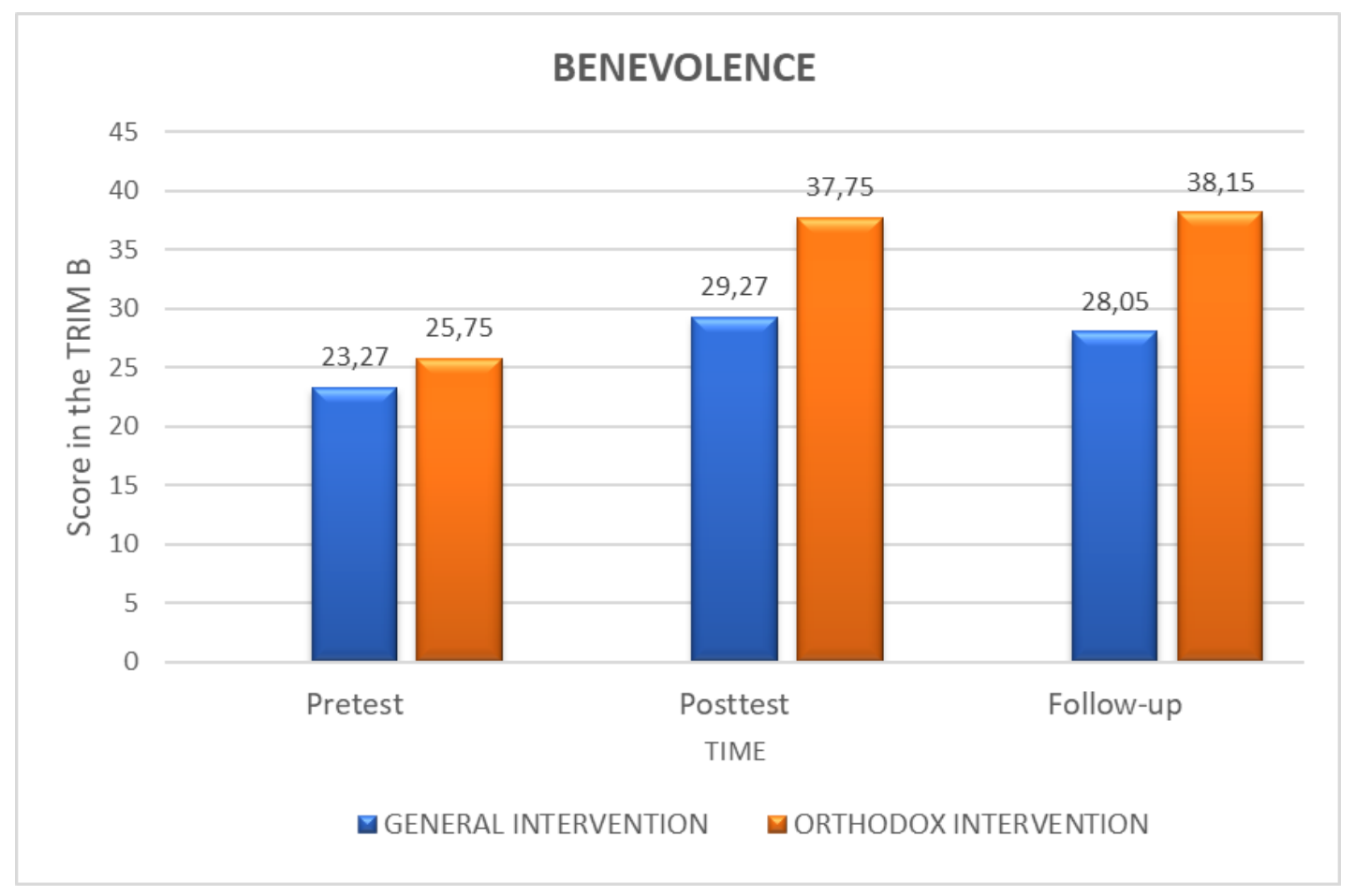

Figure 5 The score of the two groups of intervention in the Benevolence Motivation Inventory (Means).

\section{Discussion}

The purpose of this study was to examine the effectiveness of two forgiveness interventions, namely the General and the Orthodox. The research hypothesis was that participants would report increased levels of pre-dispositional forgiveness, forbearance, and overall well-being after the interventions, and participants in the Orthodox intervention would have better results than in the General. In addition, it was assumed that the positive result would be maintained for at least 2 weeks after the intervention. All hypotheses (1a, 1b, 1c) were confirmed, given that there was an increase in the overall sense of well-being and goodwill, as well as a reduction in avoidance and revenge motivations in the posttest measurements and in the follow-up after two weeks.

\subsection{The Effects of Interventions on Forgiveness}

The results showed that both interventions reinforced the participants in the development of stronger dispositional forgiveness as estimated by the Heartland (HFS) scale. These findings are consistent with previous research and suggest that certain beliefs and practices, such as the cultivation of empathy, meditation, or prayer, can facilitate forgiveness. In the present study, most participants seemed to benefit from forgiveness procedures, albeit to a different extent in each intervention [56]. We have already noted that in Greece the structure of the three factors was not confirmed. In Greece, it has been found that there are two factors. However, here we looked only at the total score of forgiveness.

Researchers of all positions and ideological directions support and promote forgiveness in the context of profit motivation as it is a source of inner peace and thus promotes mental and physical well-being [63]. However, failure to forgive is remarkable, even in people who have a strong desire 
to forgive. The topic of forgiveness is undoubtedly difficult to manage. Forgiveness is one of the most difficult achievements and it can be fragile under difficult circumstances.

Reflecting on this, many researchers have concluded that there is a close relationship between any religious faith and the level of forgiveness. People who have understood the concept of forgiveness through religious education can easily realize that forgiveness is the primary and most effective way to solve problems in human relationships [64]. Our findings agree with that conclusion and demonstrate the effectiveness of the Orthodox perspective in the cultivation and preservation of forgiveness. The Orthodox Intervention group noted significantly higher levels of forgiveness in the posttest assessment and even higher in monitoring than the secular. The effect of the Orthodox intervention on levels of forgiveness was statistically higher compared to the secular intervention with a greater difference in favor of Orthodox intervention in the following-up measurements. This is probably due to the highest motivation offered by the Orthodox faith and its long-lasting influence. This program enhanced by the Orthodox tradition presumably offered participants the opportunity to develop their spiritual powers as they were reinforced by the divine power.

\subsection{The Effects of Interventions on Well-Being}

Increased well-being, as estimated by the PERMA-Profiler scale, was found in the participants of both interventions, except that the positive effect in the follow-up was maintained only in the Orthodox intervention. The results show that the cultivation of forgiveness has an impact on the well-being, which lasts when supported by beliefs and practices of the Orthodox Tradition. The Orthodox Intervention group scored significantly higher in well-being at the posttest assessment and even higher in the following-up, thus persevering the effect of the intervention. However, the result of the intervention was not retained in the General Intervention group. The Orthodox approach has been proven to have a long-lasting dynamic that consolidates and enhances the sense of well-being over time.

In the Orthodox Tradition, forgiveness implies a profound inner change that leads to overcoming anger and internal conflicts and makes people turn their efforts on creative goals. The process of forgiving reduces anxiety and increases self-esteem, relieves someone from guilt, fear of negative situations, disappointments, and cancellations, and cultivates patience and trust. Forgiveness helps people regain their power, take responsibility and control of their feelings, gain greater awareness of justice, and thus enjoy higher levels of freedom, emotional balance and social adjustment. Forgiveness also cultivates sensitivity and interest in others, as well as understanding the perspective of others, resulting in better interpersonal relationships. Particularly, the Orthodox approach inspires the view of the other through a new light, that of the image of God, and establishes a more social way of life [50].

\subsection{The Effects of Interventions on Motivations of Avoidance, Revenge, and Benevolence}

The results showed a significant reduction in the motivations of avoidance and revenge, and increase in the motivations for benevolence in both interventions, with a significant difference in Orthodox intervention in the follow-up measurement.

These findings are consistent with previous research, whereby forgiveness is recognized as a powerful method of rupturing cycles of hostility, anger, and hatred [65]. The processes of 
forgiveness release someone from the feelings of victimization, hatred or the need for vengeance, and his wounds are healed. This results in less emotional pain when recalling the traumatic experiences of the past. Furthermore, the Orthodox approach enhances the possibility of remembrance of evil without the spirit of revenge, but with the spirit of humiliation and love. Thus, the past is transformed from a source of suffering into an opportunity for change and a source of hope.

Moreover, the process of forgiveness enhances self-esteem and self-acceptance, and in turn develops understanding and compassion even for the offender. People who forgive themselves and others can attribute to others the due appreciation and value without the sense of diminishing their own worth and integrity. They feel secure without focusing solely on their self or on the mistakes of others. On the contrary, someone who is emotionally injured often tends to spread his pain to others.

According to Hargrave and Hammer [66], forgiveness increases the sense of personal power, which implies a sense of self-efficacy and access to more effective mechanisms for dealing with insults. Forgiveness also helps to overcome dissatisfaction, bitterness, and even hatred towards those who were wrong and sometimes harsh.

\subsection{Limitations and Proposals for Future Research}

Several limitations should be noted, the main one being the limited time for the study, which left limited time for the participants to assimilate the six phases of the program. On the other hand, the processes of forgiveness have an outcome that also depends on some other factors, such as personality traits, the severity of the injustice, the size and depth of trauma, as well as the proximity of the relationship between the victim and the perpetrator. In the case of our study, a factor that could influence the outcome is the previous experience of the Orthodox tradition. All participants were Orthodox Christians as most Greek citizens are, but the level of their meaningful relationship with the church could not be verified. A limitation in this research, therefore, is the absence of queries at the beginning of the process to assess these factors in order to take them into account in the results. In addition, the sample of the study was convenience and the tools for measurement were all self-reporting scales. Additionally, there was an issue with the factorial analysis in the Transgression Related Interpersonal Motivations Inventory (TRIM) because the sample size was relatively small for a factor analysis.

It is also a limitation that there was no waiting list in our study, and it is possible that the passage of time was likely to affect the result, but the violations reported were serious enough to resolve them only with time.

The difficulty of using the internet by older adults has led to the use of the printed version of the program. Given that the Greek population is not familiar with such interventions, further research is needed on the type, content and how that can be made promising and appealing to the public.

\section{Conclusions}

Nevertheless, this is the first study to evaluate two self-directed forgiveness programs in a sample of the Greek population. The findings are promising for the ability of forgiveness 
interventions, and especially of those based on the Orthodox tradition, to improve the forgiving skills and increase mental well-being in adults.

The programs we have implemented encourage those who want to forgive to use any intellectual and religious inspiration and resources that have personal meaning. The fundamental and universal human power of forgiveness can help everyone, whether their primary motive is religious, moral, or psychological.

The primacy of the Orthodox approach has been demonstrated to even deal with serious interpersonal violations, to reduce negative emotions and promote individual dimensions of wellbeing over time. More research is also needed on Orthodox Christians. Research that would not only meet the adaption of existing interventions that have been investigated mainly in the secular context but also allow the modification of the few interventions that have been specifically adapted to Christians.

In addition, because the process and value of forgiveness are usually misunderstood or difficult to understand, it is necessary to consider introducing forgiveness in the school education and in formal school programs [67]. The Orthodox tradition of forgiveness education can play an important role in the curriculum and teacher training programs.

\section{Author Contributions}

OZ designed the study, examined all participants, and participated in the statistical processing of the data and the writing of the manuscript, under the supervision of DM. ChP and AS were involved in the examination of the psychometric properties of the PERMA-Profiler and the supervision of the study.

\section{Competing Interests}

The authors have declared that no competing interests exist.

\section{References}

1. Wade N, Hoyt W, Kidwell J, Worthington E. Efficacy of psychotherapeutic interventions to promote forgiveness: A meta-analysis. J Consulting Clin Psychol. 2014; 82: 154-170.

2. Huppert F. Psychological well-being: Evidence regarding its causes and consequences. Appl Psychol Heal Wellbeing. 2009; 1: 137-164.

3. Royal College of Psychiatrists. No health without mental health. London: Stationery Office; 2011.

4. Ingersoll-Dayton B, Campbell R, Ha J. Enhancing forgiveness: A group intervention for the elderly. J Gerontol Soc Work. 2008; 52: 2-16.

5. Ingersoll-Dayton B, Torges $\mathrm{C}$, Krause N. Unforgiveness, rumination, and depressive symptoms among older adults. Aging Mental Heal. 2010; 14: 439-449.

6. Akhtar S, Barlow J. Forgiveness therapy for the promotion of mental well-being: A systematic review and meta-analysis. Trauma Violence Abuse. 2016; 19: 107-122.

7. Silton R, Flannelly J, Lutjen J. It pays to forgive! Aging, forgiveness, hostility, and health. J Adult Develop. 2013; 20: 222-231. 
8. Turesky D, Schultz J. Spirituality among older adults: An exploration of the developmental context, impact on mental and physical health, and integration into counseling. J Religion Spirituality Aging. 2010; 22: 162-179.

9. Weng J, Zhang T, Fu $\mathrm{H}$. The effect of forgiveness intervention on the treatment of physiology disease. Chinese J Clin Psychol. 2014; 22: 564-567.

10. Li S, Shi L, Li J, Yang Y. Forgiveness intervention and its clinical application status. Chinese J Clin Psychol. 2012; 20: 132-134.

11. Wade N, Worthington E, Meyer J. A meta-analysis of group forgiveness. Handbook Forgiveness. 2005: 423-439.

12. Harris A, Thoresen C. Handbook of forgiveness 2005. New York: Brunner-Routledge; 2005. pp. 321-334.

13. Schilling $\mathrm{O}$, Wahl $\mathrm{H}$, Oswald $\mathrm{F}$. Change in life satisfaction under chronic physical multimorbidity in advanced old age: Potential and limits of adaptation. J Happiness Stud. 2013; 14: 19-36.

14. Pawlowski T, Downward $P$, Rasciute S. Subjective well-being in European countries-on the age-specific impact of physical activity. Eur Rev Aging Phys Activ. 2011; 8: 93-102.

15. Hebl J, Enright R. Forgiveness as a psychotherapeutic goal with elderly females. Psychotherapy. 1993; 30: 658-667.

16. Allemand $M$, Steiner $M$, Hill P. Effects of a forgiveness intervention for older adults. J Couns Psychol. 2013; 60: 279-286.

17. Worthington $E$, Witvliet $C$, Pietrini $P$, Miller A. Forgiveness, health, and well-being: A review of evidence for emotional versus decisional forgiveness, dispositional forgivingness, and reduced unforgiveness. J Behav Med. 2007; 30: 291-302.

18. Baskin T, Enright R. Intervention studies on forgiveness: A meta-analysis. J Counseling Develop. 2004; 82: 79-90.

19. Enright R, The Human Development Study Group. Handbook of moral behavior and development. Hillsdale: Erlbaum; 1991. pp. 123-152.

20. Worthington EL. An empathy-humility-commitment model of forgiveness applied within family dyads. J Fam Ther. 1998; 20: 59-76.

21. Worthington E. Five steps to forgiveness. New York: Crown; 2001.

22. McCullough M, Rachal K, Sandage S, Worthington E, Brown S, Hight T. Interpersonal forgiving in close relationships: II. Theoretical elaboration and measurement. J Personality Soc Psychol. 1998; 75: 1586-1603.

23. Nation J, Wertheim E, Worthington E. Evaluation of an online self-help version of the REACH forgiveness program: Outcomes and predictors of persistence in a community sample. J Clin Psychol. 2017; 74: 819-838.

24. Worthington E. The Path to Forgiveness [Internet]. 2011 [cited 1 March 2017]. Available from: https://static1.squarespace.com/static/518a85e9e4b04323d507813b/t/533c6be2e4b0cf488 5e38a3a/1396468706314/the-path-to-forgiveness-six-practical-sections-for-becoming-amore-forgiving-person.pdf.

25. Kazdin A, Rabbitt S. Novel models for delivering mental health services and reducing the burdens of mental illness. Clin Psychol Sci. 2013; 1: 170-191.

26. Lovell K, Richards D, Bower P. Improving access to primary mental healthcare: Uncontrolled evaluation of a pilot self-help clinic. Brit J Gen Pract. 2003; 53: 133-135. 
27. Greer C, Worthington E, Lin Y, Lavelock C, Griffin B. Efficacy of a self-directed forgiveness workbook for Christian victims of within-congregation offenders. Spirituality Clin Pract. 2014; 1: 218-230.

28. Harper Q, Worthington E, Griffin B, Lavelock C, Hook J, Vrana S, et al. Efficacy of a workbook to promote forgiveness: A randomized controlled trial with university students. J Clin Psychol. 2014; 70: 1158-1169.

29. Ybarra M, Eaton W. Internet-based mental health interventions. Mental Heal Serv Res. 2005; 7: 75-87.

30. Christensen H, Griffiths K, Farrer L. Adherence in internet interventions for anxiety and depression. J Med Internet Res. 2009; 11: e13.

31. Barak A, Hen L, Boniel-Nissim M, Shapira N. A Comprehensive review and a meta-analysis of the effectiveness of internet-based psychotherapeutic interventions. J Technol Human Serv. 2008; 26: 109-160.

32. Richards D, Richardson T, Timulak L, McElvaney J. The efficacy of internet-delivered treatment for a generalized anxiety disorder: A systematic review and meta-analysis. Internet Inte. 2015; 2: 272-282.

33. Kelders S, Kok R, Ossebaard H, Van Gemert-Pijnen J. Persuasive system design does matter: A systematic review of adherence to web-based interventions. J Med Internet Res. 2012; 14: e152.

34. Lampton C, Oliver G, Worthington E, Berry J. Helping Christian college students become more forgiving: An intervention study to promote forgiveness as part of a program to shape Christian character. J Psychol Theol. 2005; 33: 278-290.

35. Stratton S, Dean J, Nooneman A, Bode R, Worthington E. Forgiveness interventions as spiritual development strategies: Workshop training, expressive writing about forgiveness, and retested controls. J Psychol Christianity. 2008; 27: 347-357.

36. Worthington E, Hunter J, Sharp C, Hook J, Van Tongeren D, Davis D, et al. A psychoeducational intervention to promote forgiveness in Christians in the Philippines. J Mental Heal Couns. 2010; 32: 82-103.

37. Rye M, Pargament K. Forgiveness and romantic relationships in college: Can it heal the wounded heart?. J Clin Psychol. 2002; 58: 419-441.

38. Rye M, Pargament K, Pan W, Yingling N, Shogren K, Ito M. Can group interventions facilitate forgiveness of an ex-spouse? A randomized clinical trial. J Consulting Clin Psychol. 2005; 73: 880-892.

39. Worthington E, Hook J, Davis D, McDaniel M. Religion and spirituality. J Clin Psychol. 2011; 67: 204-214.

40. Hook J, Worthington Jr. E, Davis D, Gartner A, Jennings J, Hook J. Empirically supported religious and spiritual therapies. J Clin Psychol. 2010; 66: 46-72.

41. Worthington E, Hook J, Davis D, McDaniel M. Religion and spirituality. J Clin Psychol. 2011; 67: 204-214.

42. Worthington $E$, Lin $\mathrm{Y}, \mathrm{Ho} \mathrm{M}$. Adapting an evidence-based intervention to REACH Forgiveness for different religions and spiritualities. Asian J Psychiat. 2012; 5: 183-185.

43. McMinn M, Meek K, Dominguez A, Ryan J, Novotny K. Forgiveness motives among evangelical Christians: Implications for Christian marriage and family therapists. Marriage Fam Christian J. 1999; 2: 189-199. 
44. McMinn M, Fervida H, Louwerse K, Pop J, Thompson R, Trihub B, et al. Forgiveness and prayer. J Psychol Christianity. 2008; 27: 101-109.

45. Jones G. Embodying forgiveness: A theological analysis. Grand Rapids: Wm. B. Eerdmans Publishing Co; 1995.

46. Exline J, Worthington E, Hill P, McCullough M. Forgiveness and justice: A research agenda for social and personality psychology. Personality Soc Psychol Rev. 2003; 7: 337-348.

47. Thermos B. Mutual forgiveness and care of the other. Soul: Armos Publications; 2016. pp. 615.

48. Sophrony A. We shall see him as he is. Platina: St. Herman of Alaska Brotherhood; 2006.

49. Tes Klimakos I, Luibhéid C, Russell N, Ware T. The ladder of divine ascent. Mahwah (NJ): Paulist Press; 1982.

50. Mpelezos K. Forgiveness. Athens: Bread of Life; 2014. pp. 152-206.

51. DiBlasio FA. Christ-like forgiveness in marital counseling: A clinical follow-up of two empirical studies. J Psychol Christianity. 2010; 29: 291.

52. DiBlasio FA, Benda BB. Forgiveness intervention with married couples: Two empirical analyses. J Psychol Christianity. 2008; 27: 150-158.

53. Lin Y, Worthington E, Griffin B, Greer C, Opare-Henaku A, Lavelock C, et al. Efficacy of REACH Forgiveness across cultures. J Clin Psychol. 2014; 70: 781-793.

54. Worthington E, DiBlasio F. Promoting mutual forgiveness within the fractured relationship. Psychother Theory Res Pract Training. 1990; 27: 219-223.

55. Worthington E. A primer on intake interviews with couples. Am J Fam Ther. 1991; 19: 344-350.

56. Worthington $E$, Jennings $D$, Diblasio F. Interventions to promote forgiveness in couple and family context: Conceptualization, review, and analysis. J Psychol Theol. 2010; 38: 231-245.

57. Seligman M. Flourish: A visionary new understanding of happiness and well-being. Choice Rev Onli. 2011; 48: 48-7217.

58. Pezirkianidis C, Stalikas A, Lakioti A, Yotsidi V. Validating a multidimensional measure of wellbeing in Greece: Translation, factor structure, and measurement invariance of the PERMA Profiler. Curr Psychol. 2019; DOI: 10.1007/s12144-019-00236-7

59. Thompson L, Snyder C, Hoffman L, Michael S, Rasmussen H, Billings L, et al. Dispositional forgiveness of self, others, and situations. J Personality. 2005; 73: 313-360.

60. Moraitou D, Karadimou M, Varvarouses $M$. Mental health in the elderly: Its relation with forgiveness, affective state, and individual - demographic factors. The 1st International Conference of the Psychological Society of Northern Greece: Quality of Life and Psychology (2004 December); Thessaloniki, Greece.

61. Papadopoulou V, Lykidou S, Moraitou D, Papantoniou G. The role of gratitude and forgiveness in retirement adjustment. Hell J Psychol. 2017; 14: 199-222.

62. McCullough $M$, Hoyt $W$. Transgression-related motivational dispositions: Personality substrates of forgiveness and their links to the big five. Personality Soc Psychol Bull. 2002; 28: 1556-1573.

63. Webb J, Toussaint L, Conway-Williams E. Forgiveness and health: Psycho-spiritual integration and the promotion of better healthcare. J Health Care Chaplaincy. 2012; 18: 57-73.

64. Enright R, Santos M, Al-Mabuk R. The adolescent as forgiver. J Adolescence. 1989; E12: 95110.

65. Pritchard R. The healing power of forgiveness. Eugene: Harvest House Publishers; 2005. 
66. Hargrave T, Hammer M. Forgiveness and trauma: Working with love, justice and power for healing. Psyche En Geloof. 2011; 22: 102-111.

67. Van der Walt J, de Muynck B, Broer N, Wolhuter C, Potgieter F. The need for and possibility of a christian forgiveness education in schools. J Res Christian Ed. 2018; 27: 101-118.

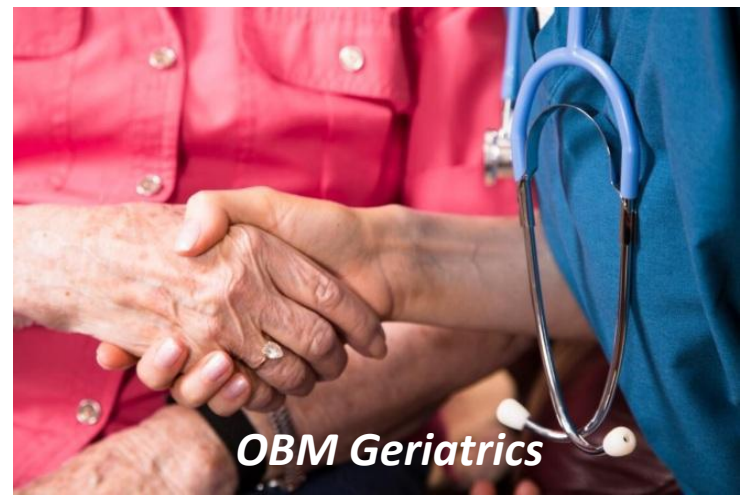

Enjoy OBM Geriatrics by:

1. Submitting a manuscript

2. Joining in volunteer reviewer bank

3. Joining Editorial Board

4. Guest editing a special issue

For more details, please visit:

http://www.lidsen.com/journals/geriatrics 